\title{
A practical model of development for China's National Quality Course Plan
}

\section{Wang Long and Stian Håklev}

Wang Long received his MA from Capital Normal University, with a thesis about the National Quality Course Plan and Open Educational Resources (OER). Since then, he has worked at implementing the National Quality Course Plan at the Chinese People's Public Security University and has also participated in a large evaluation project of Beijing City's National Quality Courses. He has published a number of papers about National Quality Courses and OER in Chinese journals, and received a scholarship for his OER research from China Open Resources for Education in 2008. Stian Håklev received his MA in comparative education from the University of Toronto, with a comparative study of the National Quality Course Plan and MIT OpenCourseWare. He is currently a PhD student at the University of Toronto researching Computer-Supported Collaborative Learning. Address for correspondence: $\mathrm{Mr}$ Stian Håklev, 115 King Edward Ave, Toronto, ON M4C 5J7, Canada. Email: stian.haklev@utoronto.ca

\begin{abstract}
The Chinese National Quality Course Plan is a large-scale project by the Ministry of Education, which has led to the production of more than 12000 courses from some 700 universities since 2003. This paper describes in detail the purpose of the project and how it is organized at all levels, including how individual courses get selected at university level, provincial level and national level. The paper discusses the similarities and differences between the Chinese project and Open Educational Resources projects around the world, including Massachusetts Institute of Technology (MIT) OpenCourseWare. The Chinese project is unique, not only because of its highly centralized organization and funding but also because its purpose is not just to produce open resources but to use the production of open resources to drive curriculum reform and quality improvement in Chinese higher education.
\end{abstract}

\section{Introduction}

At around the same time that MIT OpenCourseWare (OCW) and other OCW projects began the trend of developing Open Educational Resources (OER) organized as entire courses in 2003, China developed a large-scale project for sharing educational resources within its domestic higher education sector (MIT, 2008). This project shares the core values of openness, free in cost and sharing with other international OER projects, but there are important differences in terms of scale, implementation, types of resources offered, financing and quality assurance. The project is called guójiā jīngpinn kèchéng, roughly translated as the National Quality Course Plan, and is an important part of the National Quality Project, which aims to improve the quality of undergraduate teaching in China.

Despite the large scale of this project, very little is known about it outside of China. Most of the English-language sources that mention it assume naturally that it is another OCW project, similar to those in Korea, Japan and Taiwan, for example, with roughly the same purposes and organizational principles as in the other 44 countries implementing MIT-inspired OCW projects (see, for example, Carson, 2009 and Wiley, 2007). MIT reports themselves frequently mention the Chinese project as one of the positive impacts of the MIT OCW project (MIT OpenCourseWare, 2005). 
Among the few publications in English about the project, Han and Liu (2010) have introduced the motivations behind the project and detailed some of their research on the organization of producing courses, and Håklev (2010) has contextualized the project in the history of Chinese higher education. This paper aims to give a comprehensive overview of how the project is structured from macro- and microperspective based on a literature review, and the two authors combined 8 years of researching and being involved with the project.

\section{The National Quality Course Plan}

Throughout the last 8 years, the process of developing and sharing National Quality Courses has expanded and matured, but it is still difficult to properly define the project. China Open Resources for Education uses the English term China Quality OCW, but given the connotations of this term, it does not seem appropriate for the project (F. Wang, 2008). Although the actual resources generated by the National Quality Course Plan are very similar in form to courses found on OCW websites, the project itself is very different and cannot simply be lumped together with other OCW projects. So what is the project?

In a document that lays out the reasons for setting it up, the Chinese Ministry of Education states: "National Quality Courses are exemplary courses, which include amongst others first class teaching teams, first class educational content, first class educational approach, first class teaching material and first class teaching management." (MoE, 2003) Although this is how the project was first introduced, this description is not sufficient for an international audience to understand the meaning of the project. This paper will attempt to explain the intentions behind this definition.

The National Quality Course Plan uses the Internet to facilitate the construction and sharing of high-quality educational resources. These resources are organized as courses (including teaching materials, course plans, lesson plans, educational courseware and lesson recordings) and must be freely shared with all Chinese universities for 5 years. When reviewing the quality of courses, emphasis is put on the educational philosophy, teaching team, teaching materials, teaching methods and approaches, and teaching management and assessment; however, the most important is the course's potential to serve as an inspirational example. Universities are also encouraged to choose courses where they have unique strengths.

The courses can be divided by type and level. According to the type of university, there are undergraduate courses, vocational courses and online courses. Depending on the quality and the degree of maturity of the course, it can be chosen as a university-level course, a provincial-level course or a national-level course.

In practice, National Quality Courses refer to high-quality courses with rich Web resources that are shared openly. These courses should be under continual improvement and updating during the 5-year period. Having one's course selected as a National Quality Course at any level is a great honor for the individual teaching team, the department and the entire university.

Before the project began, many Chinese universities had already been actively developing online courses and online resources for their traditional courses (Zhao \& Jiang, 2010). The National Quality Course Plan could be seen as an extension of this trend, underlining the integration of resources, course quality, sharing and openness, and the inspirational effect of exemplary courses.

\section{The Chinese higher education Quality Project and the National Quality Course Plan} China is currently undergoing a rapid expansion of the higher education system (Altbach, 2009). In this transition from elite to mass higher education, a pressing question is how to improve the quality of teaching and train the creative and talented people that society requires. During the 
1990s, Chinese higher education experienced a series of very large-scale educational reform projects. Through these reforms, educational ideas, ways and purposes of nurturing talent, the organization of teaching, the pedagogical environment and teaching materials all underwent deep changes. In 2007, the Ministry of Education officially launched the "Project for Reform of Teaching and Improvement of Teaching Quality in Institutions of Higher Education” (usually referred to as the Quality Project) (Li, 2010; MoE, 2007). This project includes a number of features: restructuring of majors, sharing of courses and teaching materials, innovative reforms for practical training and nurturing of talent, setting up of teaching teams, the publication of teaching evaluations and data on teaching and learning, and mutual assistance between universities in Eastern China and universities in the lesser developed Western China (Zheng, 2007).

The National Quality Course Plan is not only an important part of the larger Quality Project but was also the first part of the Quality Project that got underway. It was officially launched by the Ministry of Education in April 2003 and has gone through two stages. The first stage was from 2003 to 2007, during which time 1500 national-level National Quality Courses were created, and the focus was on commonly taught basic undergraduate courses. The second stage began in 2007 when the Quality Project launched with a target of constructing 3000 national-level National Quality Courses. Many of these would be commonly taught undergraduate courses, but the program also expanded to include online distance-education courses and courses from public security and military schools.

The project has three important goals. The first is promoting the construction of national-level courses according to the "five first classes" mentioned earlier, which can serve as inspirational examples. The second is to establish National Quality Course Plan strategies for all majors and disciplines at the university, provincial and national levels. The third is promoting the open sharing of quality educational resources (Wang, 2006).

\section{The National Quality Course Plan and OER}

The National Quality Course Plan has the following characteristics when compared with other OER projects. In terms of organization, it was the Ministry of Education and the provincial bureaus of education that initiated the project and that fund it. It is organized according to a top-down model, where the Ministry of Education leads and promotes its development, and the individual universities provide some financial support. The scale of the project is very large, with more than 12000 courses having been developed, involving more than 700 universities and other institutions of higher education. Quality is not seen as an attribute of the finished course but as a continual process of improvement as the course is selected for the university-level designation, the provincial-level designation and the national-level designation.

The approach to sharing and licensing represents one important difference with traditional OER projects. Smith and Casserly (2006) believe that the use of open licenses is a necessary prerequisite for an educational resource to be "open," and The Cape Town Open Education Declaration (2007) also talks about "openly licensed" course material. However, there is no mention of open licenses in the National Quality Course Plan documents. Instead, the requirement is for courses to be openly shared for 5 years after they receive the designation. What happens to the course materials after the 5 years is not clear, which is different from most OER projects, which place no time limit on the open sharing. This also limits the kind of reuse and adaptation of the course material that, for example, Downes (2007) and Wiley (2007) have been calling for as a key to the sustainability of OER projects (Ding \& Wang, 2006).

However, the National Quality Course Plan is in a very different position from most other OER projects. The development of these resources is closely integrated with the development and improvement of university courses - indeed, it is considered as one of the basic functions of a 
university, which directly contributes to the key role of training students. After all, the project aims to achieve a number of different goals: much more than just the sharing of high-quality educational resources, the program aims to use these resources as a lever to advance the entire process of course development, encouraging advances in course design, pedagogical reform and the integration of information technology (IT) in university teaching.

\section{The development process of the National Quality Courses}

The development process can be seen both from macro- and microperspective. From a macroperspective, we can discuss how a university develops a National Quality Course Plan strategy, and from a microperspective, we can discuss the specific process involved in creating university-level, provincial-level and national-level courses.

The main phases of the development process for a National Quality Course Plan

The term National Quality Course describes the result of a course authoring process, a highquality course that has received this specific honorable designation. A National Quality Course Plan strategy refers to a continuous process of development and quality improvement.

From a macroperspective, the development of a National Quality Course Plan strategy constitutes a cycle that includes three elements: planning the development, the actual development and the evaluation of the development. The main purpose of the planning phase is to determine the objectives of the project, schedule of development, development specifications and main steps. The actual development phase consists of formulating or revising the indicators for assessment, making recommendations based on the annual assessment and launching the application, evaluation and publication of university-level, provincial-level and national-level courses. Each National Quality Course must also be allocated the proper financial resources for its development to be successful. Finally, the main task of the evaluation phase is making sure that the National Quality Courses websites are functioning properly, ensuring that course material is up to date and quality is assured, and launching targeted research projects around the creation and application of the material that aim at improving the quality and impact of the courses.

\section{Development of the three levels of National Quality Courses}

University-level courses are organized and implemented by individual universities based on their course development plans and the courses that are traditionally highly ranked internally. Although not a strict requirement, Håklev (2010) found that many National Quality Courses had previously gone through internal course evaluations and internal competitions for the "excellent course" designations that were in place at many universities before the National Quality Course Plan. In fact, some courses had been under continuous development for more than a decade before applying to the National Quality Course Plan.

From courses that have already developed good materials, have distinguishing features and can play an inspirational role for other teachers, the university administration will choose a certain number of courses and invest in their further development. The professor responsible for the course will determine the teaching team (which should consist of senior, midlevel and junior faculty, often complimented by IT staff to assist in producing the online materials) and lead the development of the course based on the specified development process for university-level courses (which usually borrows from the national-level and provincial-level procedures).

Development, evaluation and sharing of the course happen through an online platform for public demonstration and open sharing, which must be developed for each course. Depending on the level of technical support available, this may be in the shape of a common Content Management System (CMS) or a simpler individual course homepage (see examples of commercial CMSs that have sprung up to support the creation of National Quality Courses in Håklev [2010], 
pp. 47-48). Digitization and organization of course materials will lead to a course platform containing rich course modules, such as course introduction, introduction to the teaching team, course outline and calendar, lecture material (such as PowerPoint presentations), lecture recordings, experiments, reference material and course evaluation.

Initially, universities were responsible both for hosting the individual courses, as well as index pages listing to all the courses they hosted, with the Ministry of Education pages only offering links to each institution that had National Quality Courses. As part of the Quality Project in 2007, the Ministry of Education established the National Quality Courses Resource Center under the Higher Education Press, which developed the site http://www.Jingpinke.com. This portal provides individual links to every National Quality Course and also harvests valuable modules from the courses (Liu \& Wu, 2008; X. Wang, 2008).

When the course development is complete, the university usually organizes an online blind peer review of the course and, based on this, determines whether to award the university-level designation. In an example cited in Håklev (2010), the peer review was conducted by an expert group composed of subject experts from within the same university and from other highly ranked universities in the same region. Their evaluation is based mainly on the available online resources, but a supervisory committee made up of very experienced and retired teachers also goes to listen in on classes and solicits students' evaluations of the teaching materials (see also the case study from the selection process at Lanzhou City College in X. Wang [2008]).

The final announcement is made public, and anyone can both visit the course website, as well as provide feedback. If there are no strong objections to the course during this period, the decision will be made to suggest the course for a higher-level designation (provincial level and then national level).

The next step is the provincial level. The provincial bureau of education is responsible for planning the distribution of provincial-level designations based on the provincial plan for educational development and course development. The provincial government will also suggest courses for the national-level selection. The courses that enter the provincial-level selection process must already have received the campus-level designation. The province then organizes an online blind peer review by subject specialists based on provincial evaluation criteria that may differ between provinces. The courses selected are made public and awarded the provincial-level designation as well as a sum of money to support the further development of the courses.

The final step is the national-level selection, which is organized by the national Ministry of Education. It is the highest-level organization responsible for the organization and management of the National Quality Course Plan, organizing the selection of different types of courses (undergraduate courses, vocational courses and online courses), providing guidance around the entire process of developing and evaluating courses, specifying the three levels of designations and supervising the annual evaluation and selection of courses at all levels. The selection of nationallevel courses is similar to the campus-level and provincial-level processes; however, the requirements are much stricter. For a schematic view of the selection process, see Figure 1.

The Ministry of Education each year publishes detailed rubrics for evaluating the quality of submitted courses. The criteria are based around the five "first classes" and subdivided into 15 subcategories:

- teaching team, including responsible person and main lecturer;

- the composition and quality of teaching team;

- educational reform and educational research;

- the course content;

- the organization and planning of the course content;

(C) 2011 The Authors. British Journal of Educational Technology (C) 2011 BERA. 


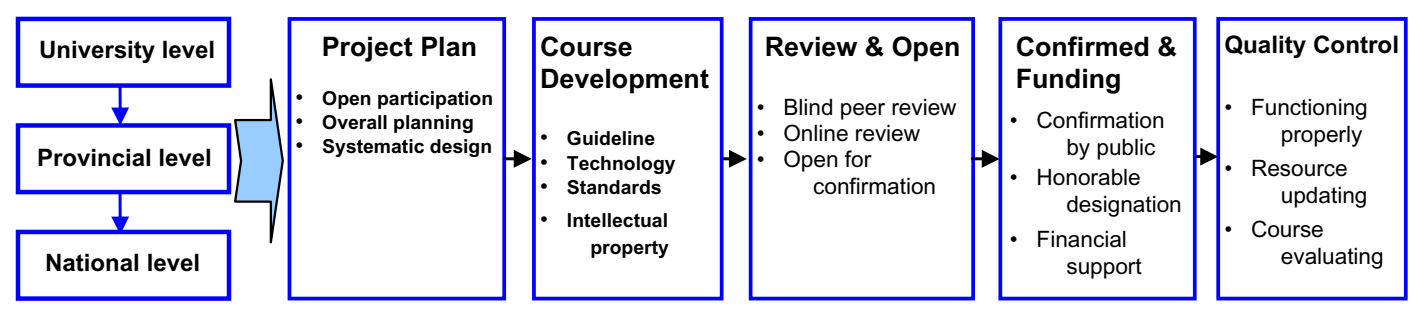

Figure 1: Pipeline for the development of National Quality Courses

- the practical components (removed in 2008);

- teaching materials and other resources;

- conditions for practical components;

- online teaching environment;

- instructional design;

- instructional approach;

- instructional practice;

- instructional outcomes - evaluation by peers and by university supervisor;

- student evaluations;

- evaluation of recorded materials (P. Wang, 2008).

The individual weights of these criteria, as well as the descriptions, change each year and reflect the changing priorities of the Ministry of Education. For example, the explanation for the criteria "evaluation of recorded materials" changed from specifying "dignified bearing, clear sound, full of teaching enthusiasm, lively class atmosphere, high student participation rate and effective student-teacher interaction" in 2003 to asking for "influential teaching which attracts students attention, enlightens and inspires thinking, association and creativity" in 2004 (Ibid., 39).

From the description earlier, we can see that the National Quality Courses are awarded different levels of designations (which reflects their level of maturity). The financial support arrives after the course has already been developed, which means that the university first has to use its own money to invest in course development before the course can receive additional support when selected to higher levels. This is congruent with the original intent of the program, which was to stimulate universities to invest more in course development.

The three levels of selection follow similar processes, and in practice, to improve the linkages between the three levels, most campus-level and provincial-level selections employ the same standards and evaluation criteria as the national-level selection. This serves to raise the quality of courses at all levels. In addition, as the entire process of development, sharing and peer review of courses is implemented through the Internet, the technology demands are quite high. The focus on digitization of resources, teaching and learning in online settings, communication between students and teachers, and generative assessments all help promote the integration of IT with teaching and learning in higher education.

The historical growth of the National Quality Course Plan

The project, which is currently in the end of its second phase, has grown rapidly, and from 2003 to 2010, 3790 national-level courses have been produced, including 2528 undergraduate courses, 1037 vocational courses and 209 online courses. The project covers more than 700 institutions of higher education in every part of China. In addition to the national-level courses, more than 6000 provincial-level courses and a large number of campus-level courses have been produced (The National Quality Course Plan, 2010). See Table 1 for an overview of the subject areas covered. 
Table 1: Overview of courses at the http://www.jingpinke.com National Quality Courses portal

\begin{tabular}{lccc}
\hline Undergrad & Courses & \multicolumn{1}{c}{ Vocational } & Courses \\
\hline Engineering & 3908 & IT and communications & 879 \\
Physics & 3023 & Manufacturing & 851 \\
Literature & 1638 & Finance & 810 \\
Medicine & 1452 & Foundational courses & 508 \\
Management & 1141 & Culture and education & 488 \\
Economics & 700 & Civil-engineering construction & 346 \\
Law & 665 & Agricultural & 290 \\
Education & 601 & Medicine and hygiene & 270 \\
Agriculture & 598 & Biochemistry and pharmacy & 240 \\
Marxism and moral character & 301 & Arts, design and media & 207 \\
History & 201 & Light manufacturing & 150 \\
Cultural studies and politics & 114 & Material and energy & 148 \\
Philosophy & 101 & Tourism & 141 \\
& & Transportation and logistics & 129 \\
& & Resource development and extraction & 93 \\
& & Public management & 89 \\
& & Law & 64 \\
& & Environmentalism, climate and security & 55 \\
& & Public security & 42 \\
& & Irrigation and water conservancy & 37 \\
\hline
\end{tabular}

IT, information technology.

In 2007, the Ministry of Education launched the National Quality Course Plan in distance education and within 4 years of operation had already evaluated 209 national-level online courses. The evaluation of online courses puts more focus on course resources fit for self-learners, the teaching and learning process, and the design of learning support. This is natural as distance education in China has several key features distinguishing it from traditional university education: it has very high student numbers and is mainly focused on adult learners that need practical and vocationally oriented training (Zeng, Zeng \& Fan, 2007). Many of these are working professionals, who either need the training for their work or are studying for interest.

\section{The practical models of developing National Quality Courses}

The project appeared in the context of rapid development of the Chinese higher education system, which drastically expanded in size and entered the phase of mass higher education. At the same time, the use of IT in higher education increased quickly. Given this background, the project is characterized by how it pulled together all levels of higher education administrations and individual universities in promoting educational reform (Liu, 2009). The project's strength is the strong support it has received in terms of policy, administration and management, human resources, finances and technical assistance.

The project could both be described as both top-down and bottom-up. The three-level structure of university, provincial and national levels results in a pyramid-shaped distribution, where courses are voluntarily promoted level for level by individual universities and professors and can be described as a bottom-up approach. However, the Ministry of Education is responsible for the planning of the project, formulating policy, funding, organizing peer review and monitoring quality, just as it has the general responsibility for guiding the development of higher education in China. From this perspective, the project can be said to be mainly top-down (L. Wang, 2008a). We will compare the project with a number of other important international OER projects, using a graph with the practical organization of the project on one axis and the openness of the 


\section{Top to Down}

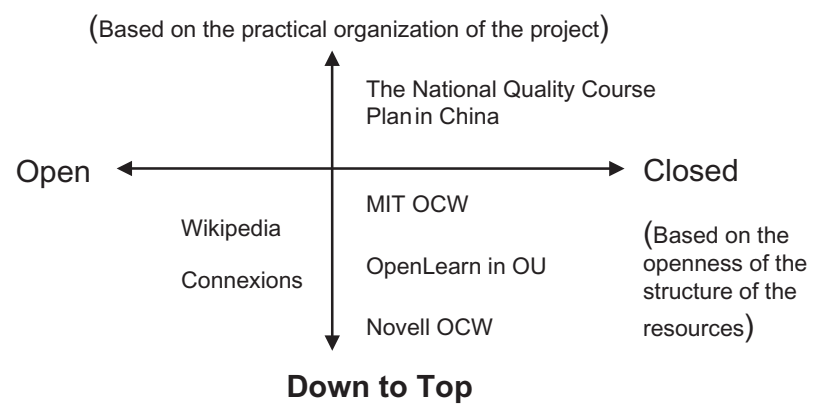

Figure 2: Practical models of development: National Quality Courses and other typical OER projects (OCW, OpenCourseWare; OER, Open Educational Resources; OU, The Open University, UK)

structure of the resources on the other, as seen in Figure 2, and using a table comparing different international OER projects from a variety of angles, as seen in Table 2. From this table, we can see that the project ends up on the side of top-down when it comes to organization. When it comes to organization of resources, courses are used as the basic organizational principle, with a closed and predetermined structure. These organizational features of the project are both tightly linked with the macrostructure of Chinese higher education as a whole, as well as with the traditional culture of China.

For the National Quality Courses Project, openness and sharing are the result of a valuable process and not the only goals. From beginning to end, the main focus is not on the publishing and sharing of digital resources, rather this publishing and sharing is used as a lever to promote the integrated development of courses. With the integrated development of courses, we mean two things. First, at the individual course level, the project promotes the improvement of educational ideals, teaching team, teaching method and approach, and course management and examination. Second, at the national level, the project aims to produce a number of top-quality courses that can work as inspirational examples for others to promote improvement and reform of all university courses, as well as the increased and improved usage of educational technology, leading to the improvement of course quality.

The quality of the resources shared is the raison d'etre for the project. To achieve and maintain this quality, the project employs a number of measures, which we can separate into internal quality measures (within the course) and external quality measures (external evaluation and control) (L. Wang, 2008b). Internal quality is achieved by adhering to project quality standards, making sure that courses live up to educational and academic requirements, are at the forefront of their discipline and are easy to use.

External quality control is achieved through the stepwise evaluation and selection at different levels. This selection is very competitive, and only courses with distinguishing features, excellent quality, rich resources and the potential to be inspirational models will be selected for the highest levels. Details of how this process works are listed earlier in the section on course development and selection. External quality measures also include the targeted control of development, publishing, updating and use of course material carried out by the Ministry of Education.

There are a number of factors that ensure the smooth operation of the project. First, the institutional factors: formulating a system of norms and standards for the peer review of applications, helping universities to institute policies that support the project and striving to establish mechanisms for the long-term promotion of course creation and development. Next is the systematic 


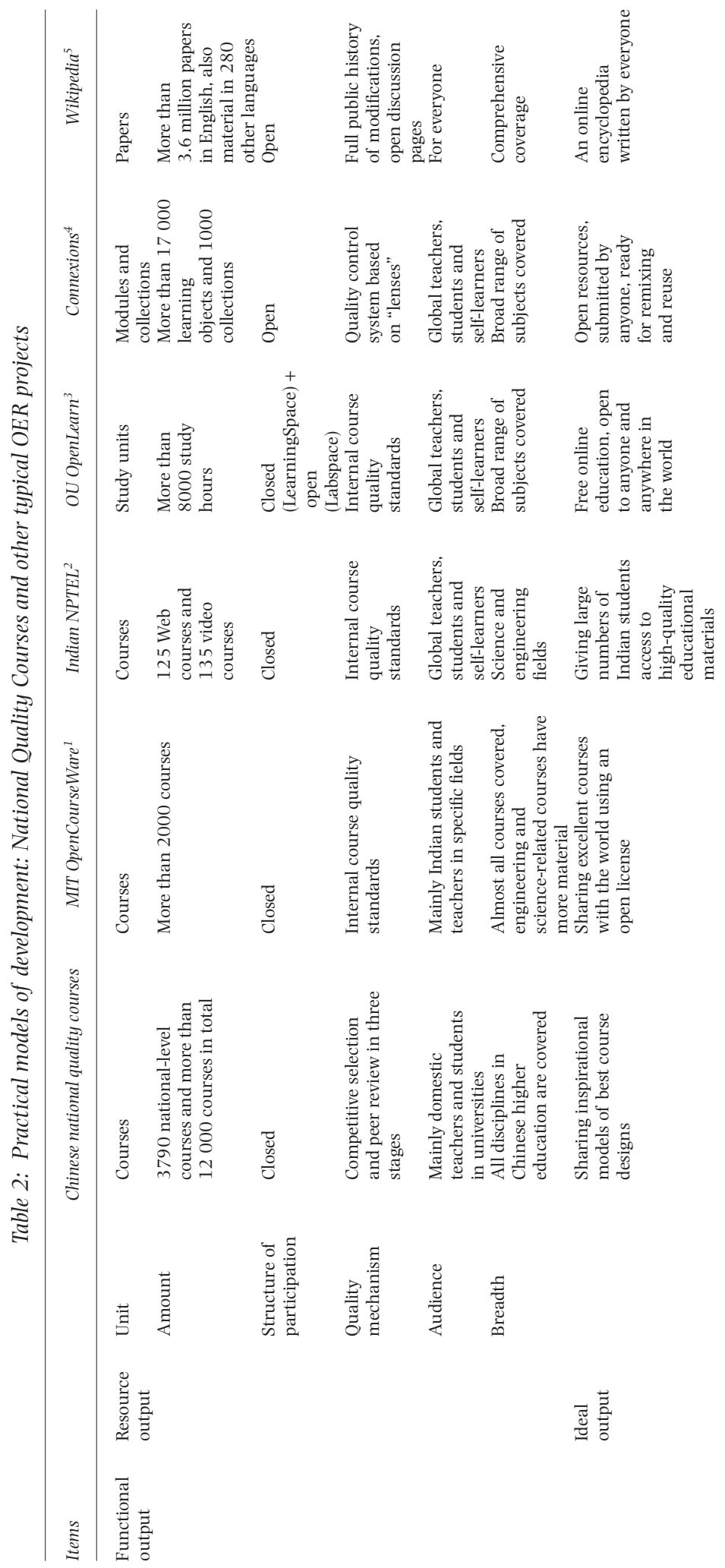




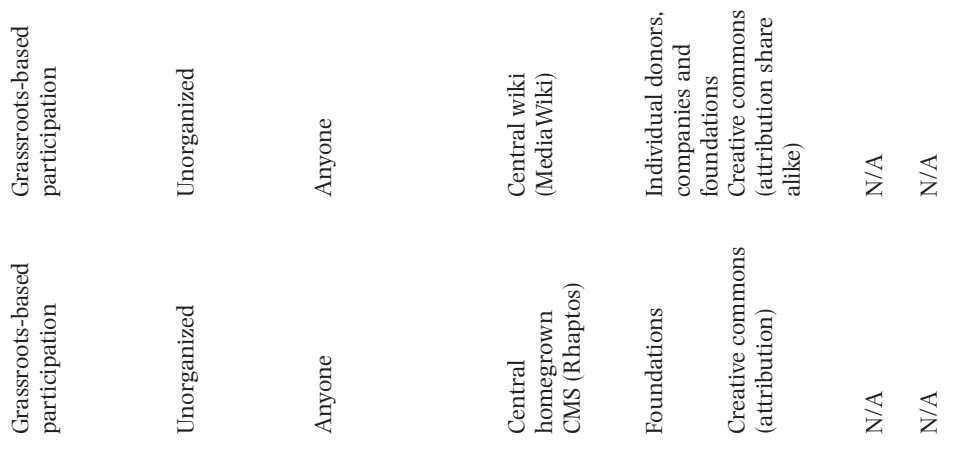

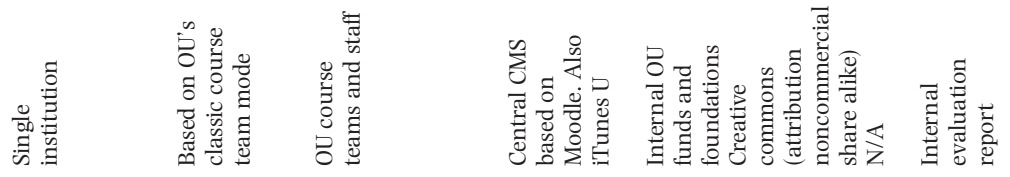
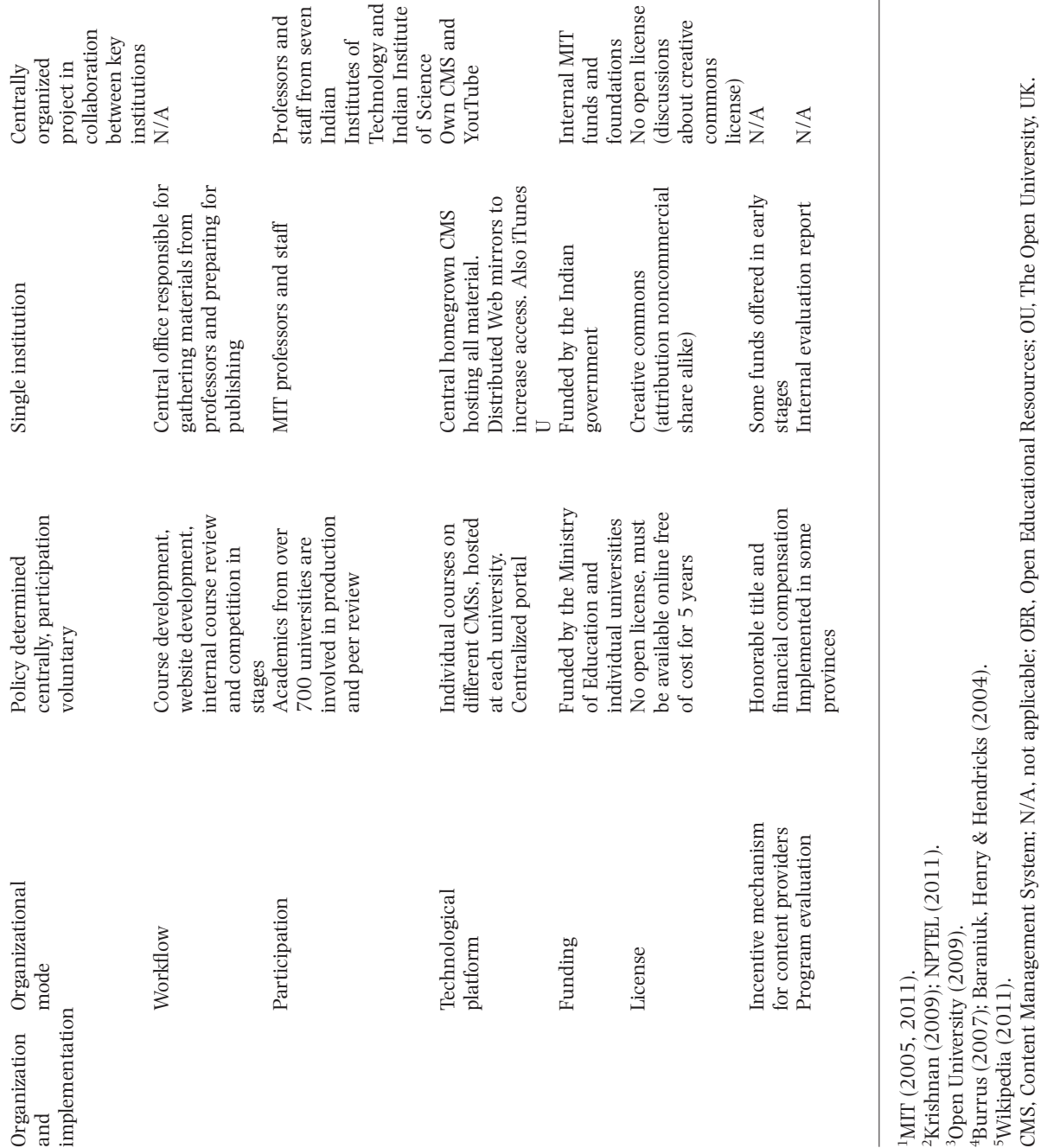

(C) 2011 The Authors. British Journal of Educational Technology (C) 2011 BERA. 
design of the project: the top-down organization, the process of proposing, reviewing and publishing, the gradual promotion from one level to the next, the practice of first constructing the courses and then getting financial support afterwards, and the encouragement of bestowing honors on courses.

These factors all contribute to the transparent, orderly, efficient and sustainable operation of the project. It is also characterized by a stable and sufficient source of funding, in which aspect it differs from most other OER projects, which usually rely on raising their own funds or on contributions from foundations (see Table 2). There are specific funds set aside for the development of National Quality Courses, and each level of operations is able to receive sufficient funding for the execution of the project. The project is organically embedded in the development plans and daily work of all participating institutions and receives sufficient support in terms of human resources, technical support, and organization and management.

The development of the course resources is closely integrated with the formal class teaching in China, and this process, which can be described as an integrated process of developing and sharing, is also one of the characteristics of the project. On one hand, National Quality Course material at any level can be used directly in the class in which they were generated, but the teaching of similar classes at other universities can also benefit from these resources. In addition, National Quality Courses also lead the way in terms of course development, and the quality norms established can inspire the development of other related courses on campus. As the goal of the project is to create excellent examples, which will inspire all other courses to improve in quality, the intimate connection with the formal higher education system is a necessity.

\section{Conclusion}

The National Quality Course Plan has developed its own very particular characteristics, and this can enrich our understanding of OER development practices. The project continues to develop the core ideas of openness and sharing, and takes advantage of educational technology to create a very large amount of resources in a way that is tightly integrated with teaching in formal higher education. At the same time, it does not only aim to produce high-quality open resources for sharing but also aim to break new ground in the realization of scale and organization (organization in different types of courses and the three-level structure) of OER. At the university level, provincial level and national level, the project has already led to the production of more than 12000 courses, separated into undergraduate, vocational and online courses.

The project has also established new norms for evaluating course quality, promoted the use of educational technology in teaching and learning, and improved all factors of course designtogether the project was able to spur the teaching reform, which is currently taking place in Chinese higher education. This open sharing of teaching practices, organizational practices and evaluation practices is much more important than the mere sharing of open resources.

\section{A sustainable open sharing practice}

There are two important factors in the sustainability of an OER project: internal (the intrinsic potential for sustainability) and external (the external factors supporting the sustainability of the project). The features of the National Quality Course Plan mentioned earlier, such as strict quality norms, three levels of selection and integration with formal class teaching, all contribute to the potential for internal sustainability. On the other hand, external factors, such as the favorable policies put in place by the Ministry of Education and participating institutions, the stable funding source and the way the project is integrated as a routine in the work of the institutions, all contribute to the potential for external sustainability. Above all, the project perfectly tallies with the main trends in Chinese higher education: the increased focus on teaching and learning 
(including course quality), promoting educational reform and innovation (including course reform and increased use of educational technology), and the inexorable march towards mass higher education.

As an example of the distinct focus of the Chinese project, Håklev (2010) interviewed a number of professors and administrators on the impact of having their courses selected as Top Quality Courses and found that most responses centered on the transformative production process itself. This is a significant difference from how most OER projects are conceived.

The National Quality Course Plan has many unique characteristics, to a large extent, because it developed in a national system of higher education, which not only has its own distinct history and social context but is currently undergoing one of the largest transitions the world has ever seen. As such, the project is uniquely fit to fulfill its role in the Chinese context. Despite this, there might be many lessons learn from this experiment that can be applied to international OER efforts, particularly given the recent announcement of a 4-year \$2 billion US Department of Labor grant for Community Colleges to create OER (Department of Labor, 2011).

The authors hope that this paper will lead to increased interest in the Chinese project and further research. Despite a large number of papers written in Chinese, there is still a need for rigorous assessments of the impact of the project-it is out of scope for the current paper to assess whether the stated objectives have been met, but this is clearly of interest to many.

\section{References}

Altbach, P. G. (2009). One-third of the globe: the future of higher education in China and India. Prospects, $39,1,11-31$.

Baraniuk, R., Henry, G. \& Hendricks, B. (2004). Peer to peer collaboration with connexions. EDUCAUSE 2004 Annual Conference, Denver, CO.

Burrus, C. S. (2007). Connexions: an educational resource for the 21st century. Educational Technology Magazine, 47, 6, 9-13.

Carson, S. (2009). The unwalled garden: growth of the OpenCourseWare consortium, 2001-2008. Open Learning, 24, 1, 23-29.

Department of Labor (2011). US Labor Department encourages applications for Trade Adjustment Assistance Community College and Career Training Grant Program. United States Department of Labor. Retrieved May 13, 2011, from http://www.dol.gov/opa/media/press/eta/eta20101436.htm

Ding, X. \& Wang, L. (2006). Beijing shi jingpin kecheng wangshang ziyuan yunxing qingkuang zhuanti diaoyan ji zhuyao jielun [Special investigation report and key conclusions on the excution of Beijing City National Quality Courses online materials]. Zhongquo Daxue Jiaoxue [China University Teaching], 5, 22-25.

Downes, S. (2007). Models for sustainable open educational resources. Interdisciplinary Journal of Knowledge and Learning Objects, 3, 29-44.

Håklev, S. (2010). The Chinese National Top Level Courses Project: using open educational resources to promote quality in undergraduate teaching. MA thesis, OISE, University of Toronto.

Han, X. \& Liu, Y. (2010). Educational technology and the National Quality Course Plan in China. British Journal of Educational Technology, 41, 4, 614-617.

Krishnan, M. S. (2009). NPTEL: a programme for free online and open engineering and science education. International Workshop on Technology for Education, Bangalore. DOI 10.1109/T4E.2009.5314112.

Li, B. (October 7, 2010). Wo guo gaoxiao benke jiaoxue "zhiliang gongcheng" dadao yuqi mubiao [Our country's university teaching "quality project" reached its targets]. Zhongguo qingnian bao [China Youth Daily]. Retrieved March 25, 2011, from http://zqb.cyol.com/content/2010-07/10/content_3319096.htm

Liu, L. (2009). Lun jingpin kecheng de tezheng [Research on features of National Quality Course Plan]. Gaodeng Jiaoyu Yanjiu [Journal of Higher Education], 30, 3, 82-86.

Liu, L. \& Wu, C. (2008). Cong Jingpin kecheng de jianshe dao gongxiang yingyong de kuayue yu fazhan"Guojia Jingpin kecheng jicheng xiangmu" jieshao [From the construction of National Quality Courses to the application and use- "Introduction to the integrated program of National National Quality Courses"]. Zhongguo Jiaoyu Xinxihua [China Education Info], 8, 4-7.

MIT (2005). 2005 Program evaluation findings report. MIT OpenCourseWare. Retrieved May 14, 2011, from http://ocw.mit.edu/ans7870/global/05_Prog_Eval_Report_Final.pdf

MIT (2008). Our history. MIT. Retrieved March 23, 2011, from http://ocw.mit.edu/about/our-history/ 
MIT (2011). Monthly report. MIT OpenCourseWare. Retrieved May 14, 2011, from http://ocw.mit.edu/ about/site-statistics/monthly-reports/MITOCW_DB_2011_02.pdf

MIT OpenCourseWare (2005). 2005 Program evaluation findings report. Boston, MA: MIT OpenCourseWare. Retreived March 23, 2011, from http://ocw.mit.edu/ans7870/global/05_Prog_Eval_Report_Final.pdf

MoE (2003). Jiaoyubu guanyu qidong gaodeng xuexiao jiaoxue zhiliang yu jiaoxue gaige gongcheng jingpin kecheng jianshe gongzuo de tongzhi [Notice of initiating the project of Building the National National Quality Courses in the Teaching Quality and Reform Plan in Chinese universities]. Ministry of Education of the People's Republic of China. Retrieved March 21, 2011, from http://www.zlgc.org/Detail.aspx?Id=1048

MoE (2007). Jiaoyubu caizhengbu guanyu shixian gaodeng xuexiao benke jiaoxue zhiliang yu jiaoxue gaige gongcheng de yijian [Opinions of the Ministry of Education and the Ministry of Finance about implementing the Project for Reform of Teaching and Improvement of Teaching Quality in Institutions of Higher Education]. Ministry of Education of the People's Republic of China. Retrieved March 21, 2011, from http://jw. nju.edu.cn/oldweb/JiaoGai/KeChengJianShe/JiaoGao20031.htm

National Quality Course Plan (2010). The Quality Courses Project (2003-2009). Retrieved August 19, 2010, from http://www.jpkcnet.com/new

NPTEL (2011). FAQ. National program for technology enhanced learning. Retrieved May 14, 2011, from http://www.nptel.iitm.ac.in/faq.php

Open University (2009). OpenLearn research report 2006-2008. Open University.

Smith, M. S. \& Casserly, C. M. (2006). The promise of open educational resources. Change: The Magazine of Higher Learning, 38, 5, 8-17.

The Cape Town Open Education Declaration (2007). Retrieved March 23, 2011, from http://www. capetowndeclaration.org/read-the-declaration

Wang, F. (2008). Kaifang jiaoyu ziyuan: linian, xianzhuang yu qianyan [Open education resources - concept, status and frontier]. Keynote presented at the 22nd Annual Conference of the Asian Association of Open Universities, Tianjin, China. Retrieved March 23, 2011, from http://aaou.tjrtvu.edu.cn/wenji.rar

Wang, L. (2006). Zhongguo gaodeng jiaoyu jingpin kecheng ziyuan gongxiang de xianzhuang,wenti, duice yu xiangguan fenxi [Open and sharing of online resources from China National Elaborate Courses in higher education: actuality, challenges, countermeasures and correlative analysis]. Master's degree dissertation of Capital Normal University.

Wang, L. (2008a). Shijie kaifang jiaoyu ziyuan shijiaoxia de jingpin kecheng jianshe xiangmu jiedu [The interpretation on the project of China Quality OCW: practice from China under the perspective of the opening and sharing of open educational resources]. Paper presented at the 2008 International Open Education Conference, Dalian, China.

Wang, L. (2008b). Zhongguo jingpin kecheng jianshe he jiaoyu ziyuan kaifang gongxiang yanjiu [Research on the project of China Quality OCW and Open Educational Resources]. CORE 2008 scholarship program.

Wang, P. (2008). 2003-2008 nian guojia jingpin kecheng pinggu zhibiao tixi de bianhua yu qushi fenxi [Analysis of the change and trends in evaluation indicators of the National Quality Course Plan from 2003-2008]. Dangdai Jiaoyu Kexue [Contemporary Educational Science], 15, 38-40.

Wang, X. (2008). Qianyi jingpin kecheng zai jiaoxue gongzuo zhong de zuoyong [Primary discussing the use of National Quality Courses in the process of teaching]. Gansu Keji Zongheng [Gansu Scientific and Technical], 1, 136-137.

Wikipedia (2011). Wikipedia: About. Wikipedia. Retrieved May 14, 2011, from http://en.wikipedia.org/wiki/ Wikipedia:About

Wiley, D. (2007). On the sustainability of open educational resource initiatives in higher education. Paper commissioned by the OECD's Centre for Educational Research and Innovation (CERI) for the project on Open Educational Resources. Retrieved August 19, 2010, from http://www.oecd.org/dataoecd/33/9/ 38645447.pdf

Zeng, H., Zeng, D. \& Fan, X. (2007). Jiyu jingpin kecheng pingshen zhibiao tantao wangluo jiaoyu ziyuan de jianshe yu gongxiang [Based on quality standards of network course to explore e-learning resources building and sharing]. Zhongguo Yuancheng Jiaoyu [Distance Education in China], 10, 47-52.

Zhao, G. \& Jiang, Z. (2010). From e-campus to e-learning: an overview of ICT applications in Chinese higher education. British Journal of Educational Technology, 41, 4, 574-581.

Zheng, J. (2007). Shenhua jiaoxue zhiliang gongcheng, zhuoli tuijin jiaoyu chuangxin [Deepening teaching quality project and focusing on promoting education innovation]. Gaodeng Gongcheng Jiaoyu Yanjiu [Research in Higher Education of Engineering], 6, 68-71. 